\title{
Intra- and Inter-Pandemic Variations of Antiviral, Antibiotics and Decongestants in Wastewater Treatment Plants and Receiving Rivers
}

\author{
Andrew C. Singer ${ }^{1 *}$, Josef D. Järhult ${ }^{2}$, Roman Grabic ${ }^{3,4}$, Ghazanfar A. Khan ${ }^{3}$, Richard H. Lindberg ${ }^{3}$, \\ Ganna Fedorova $^{3,4}$, Jerker Fick ${ }^{3}$, Michael J. Bowes', Björn Olsen ${ }^{2,5}$, Hanna Söderström ${ }^{3}$
}

1 Natural Environment Research Council, Centre for Ecology and Hydrology, Wallingford, United Kingdom, 2 Section of Infectious Diseases, Department of Medical Sciences, Uppsala University, Uppsala, Sweden, 3 Department of Chemistry, Umeå University, Umeå, Sweden, 4 University of South Bohemia in Ceske Budejovice, Faculty of Fisheries and Protection of Waters, South Bohemian Research Center of Aquaculture and Biodiversity of Hydrocenoses, Vodnany, Czech Republic, $\mathbf{5}$ Section for Zoonotic Ecology and Epidemiology, School of Natural Sciences, Linnaeus University, Kalmar, Sweden

\begin{abstract}
The concentration of eleven antibiotics (trimethoprim, oxytetracycline, ciprofloxacin, azithromycin, cefotaxime, doxycycline, sulfamethoxazole, erythromycin, clarithromycin, ofloxacin, norfloxacin), three decongestants (naphazoline, oxymetazoline, xylometazoline) and the antiviral drug oseltamivir's active metabolite, oseltamivir carboxylate (OC), were measured weekly at 21 locations within the River Thames catchment in England during the month of November 2009, the autumnal peak of the influenza $\mathrm{A}[\mathrm{H} 1 \mathrm{~N} 1]$ pdm09 pandemic. The aim was to quantify the pharmaceutical response to the pandemic and compare this to drug use during the late pandemic (March 2010) and the inter-pandemic periods (May 2011). A large and small wastewater treatment plant (WWTP) were sampled in November 2009 to understand the differential fate of the analytes in the two WWTPs prior to their entry in the receiving river and to estimate drug users using a wastewater epidemiology approach. Mean hourly OC concentrations in the small and large WWTP's influent were 208 and $350 \mathrm{ng} / \mathrm{L}$ (max, 2070 and $550 \mathrm{ng} / \mathrm{L}$, respectively). Erythromycin was the most concentrated antibiotic measured in Benson and Oxford WWTPs influent ( $\max =6,870$ and $2,930 \mathrm{ng} / \mathrm{L}$, respectively). Napthazoline and oxymetazoline were the most frequently detected and concentrated decongestant in the Benson WWTP influent (1650 and $67 \mathrm{ng} / \mathrm{L}$ ) and effluent (696 and $307 \mathrm{ng} / \mathrm{L})$, respectively, but were below detection in the Oxford WWTP. OC was found in 73\% of November 2009's weekly river samples ( $\max =193 \mathrm{ng} / \mathrm{L}$ ), but only in $5 \%$ and $0 \%$ of the late- and inter-pandemic river samples, respectively. The mean river concentration of each antibiotic during the pandemic largely fell between 17-74 $\mathrm{ng} / \mathrm{L}$, with clarithromycin ( $\mathrm{max}=292 \mathrm{ng} / \mathrm{L})$ and erythromycin $(\max =448 \mathrm{ng} / \mathrm{L})$ yielding the highest single measure. In general, the concentration and frequency of detecting antibiotics in the river increased during the pandemic. OC was uniquely well-suited for the wastewater epidemiology approach owing to its nature as a prodrug, recalcitrance and temporally- and spatially-resolved prescription statistics.
\end{abstract}

Citation: Singer AC, Järhult JD, Grabic R, Khan GA, Lindberg RH, et al. (2014) Intra- and Inter-Pandemic Variations of Antiviral, Antibiotics and Decongestants in Wastewater Treatment Plants and Receiving Rivers. PLoS ONE 9(9): e108621. doi:10.1371/journal.pone.0108621

Editor: Peter P. Fong, Gettysburg College, United States of America

Received June 5, 2014; Accepted August 20, 2014; Published September 25, 2014

Copyright: (c) 2014 Singer et al. This is an open-access article distributed under the terms of the Creative Commons Attribution License, which permits unrestricted use, distribution, and reproduction in any medium, provided the original author and source are credited.

Data Availability: The authors confirm that all data underlying the findinas are fullv available without restriction. All raw data has been made freely available at http://doi.org/10.5285/8af983e4-e97d-4c07-a34d-753243fa283b and at http://eidchub.ceh.ac.uk/metadata/8af983e4-e97d-4c07-a34d-753243fa283b

Funding: The authors received funding for the collection and analysis from the Swedish Research Council Formas, the Natural Environment Research CouncilKnowledge Transfer (PREPARE) Initiative contract NE/F009216/1, CEH Science Budget, the Ministry of Education, Youth and Sports of the Czech Republic CENAKVA No. CZ.1.05/2.1.00/01.0024 and the Grant Agency of the University of South Bohemia No. 047/2010/Z. The authors received in-kind support from G.F.F. Hoffman La Roche Ltd. through donated deuterated OC. The funders had no role in study design, data collection and analysis, decision to publish, or preparation of the manuscript.

Competing Interests: The authors received in-kind support from G.F.F. Hoffman - La Roche Ltd. through donated deuterated OC. Andrew Singer is on the PLOS ONE Editorial Board. This does not alter the authors' adherence to PLOS ONE Editorial policies and criteria. The authors have no other competing interests.

* Email: acsi@ceh.ac.uk

\section{Introduction}

Pandemics are unique public health emergencies that can result in a large sudden increase in the use of a restricted set of pharmaceuticals within a short time period. In the case of an influenza pandemic, antiviral use will greatly exceed interpandemic use in most countries by several orders of magnitude, as few countries maintain significant inter-pandemic usage-Japan being a notable exception [1]. Depending on the severity of the pandemic, antibiotics have the potential to significantly exceed inter-pandemic usage for the treatment of secondary bacterial respiratory infections [2]. Decongestant usage is also predicted to increase with an increase in upper- and lower-respiratory tract infections [3].

Antibiotics, antivirals and decongestants are typically excreted as a large percentage of the parent dose in their bioactive form (mean: $82 \pm 22 \%$ for all drugs in this study (Table 1)) [4,5]. The large load and high concentration of bioactive pharmaceuticals entering the wastewater and receiving rivers from widespread human consumption and excretion during a pandemic can potentially disrupt (micro)organisms through non-target effects 
[6-12] and cause the failure of wastewater treatment plants (WWTPs) to treat effluent to the required standard [13,14], hasten the generation of antiviral resistance in wildfowl and other influenza-susceptible organisms [15-18], and accelerate the generation and spread of (novel) antibiotic resistance in the environment $[2,19,20]$.

In this study, we measured eleven antibiotics, one antiviral and three decongestants (see Table 1) weekly at 21 locations within the River Thames catchment (Fig. 1) in England during the month of November 2009, the autumnal peak of the influenza A[H1N1]pdm09 pandemic. The aim was to quantify the pharmaceutical response to the pandemic and compare this to drug use during the late pandemic (March 2010) and the interpandemic periods (May 2011). One relatively large wastewater treatment plant (WWTP) in Oxford, UK employing activated sludge wastewater treatment and one relatively small WWTP in Benson, UK, employing trickle-bed wastewater treatment were sampled hourly for 24-h in November 2009 to 1) understand the differential pharmaceutical use patterns among the people within the WWTP catchments during the pandemic, 2) characterize the fate of the analytes in the two very different WWTPs prior to their entry in the receiving River Thames, and 3) examine the suitability of employing a wastewater epidemiology approach for the estimation of drug users within the Oxford and Benson WWTP populations.

\section{Experimental Section}

\section{Wastewater Treatment Plant Characterisation}

The Benson WWTP serves a population of 6,230 people with a consented dry weather flow (DWF) of $2,517 \mathrm{~m}^{3} / \mathrm{d}$ and an annual average DWF of $1,368 \mathrm{~m}^{3} / \mathrm{d}$ (Fig. 1 and Fig. S1 in File S1). The Benson WWTP has a hydraulic retention time of 7-8 h at DWF and consists of trickling filters as the main biological treatment step. Oxford WWTP serves a population of 208,000 with a consented DWF of $50,965 \mathrm{~m}^{3} / \mathrm{d}$ and an annual mean DWF of $38,000 \mathrm{~m}^{3} / \mathrm{d}$ (Fig. 1 and Fig. S1 in File S1). The Oxford WWTP has a hydraulic retention time of 15-18 h, and utilizes activated sludge as the main biological treatment step. Both WWTPs have primary and secondary sedimentation steps. Both Oxford and Benson WWTPs feed into the main stem of the River Thames (Fig. 1), separated by approximately 10 miles.

\section{Wastewater Treatment Plant Sampling}

The sampling of all analytes (Table 1) in Benson and Oxford WWTP was performed during a 24-hour period spanning 10-11 November 2009. An additional 24-h sampling was initiated on May 11, 2011 from only the Benson WWTP effluent for the primary purpose of confirming the background concentration of the antiviral, oseltamivir carboxylate (OC), during the interpandemic period. The pandemic officially ended on August 10, 2010, hence, the expectation was that pharmaceutical use in the study catchments in May 2011 would reflect inter-pandemic pharmaceutical usage [21]. An automated sampler was used to recover time-proportional samples (approximately $750 \mathrm{ml}$ ) of influent and effluent every hour for 24 hours. Samples were aliquoted into triplicate $50-\mathrm{ml}$ borosilicate glass vials with PTFElined caps and immediately stored at $-80^{\circ} \mathrm{C}$ until analysis.

\section{River Sampling}

Grab samples were acquired within $250 \mathrm{ml}$ borosilicate brown glass bottles at the end of a $1.5 \mathrm{~m}$-long sampling rod at 21 river locations within the River Thames catchment (Fig. 1). Sampling was undertaken on November 3, 11, 17, and 24, 2009, as well as on March 15, 2010 (late-pandemic period) and May 11, 2011 (inter-pandemic period). These sites are part of the CEH Thames Initiative Research Platform [22]. Samples were transported from the field to the laboratory within 6 hours and transferred into 50$\mathrm{ml}$ borosilicate glass vials with PTFE-lined caps, in triplicate. The samples were stored at $-80^{\circ} \mathrm{C}$ until analysis.

Table 1. Drug dosage, pharmacokinetics and limit of quantification (LOQ) of study analytes.

\begin{tabular}{|c|c|c|c|c|c|}
\hline ATC Code & Drug & Class of pharmaceutical & $\mathrm{ADQ}^{\mathrm{a}}(\mathbf{g})$ & $\%$ excreted $^{\mathbf{b}}$ & LOQ (ng/L) \\
\hline J01FA10 & Azithromycin & Macrolide antibiotic & 0.5 & $85 \%$ & 1 \\
\hline J01DD01 & Cefotaxime & Third-generation cephalosporin antibiotic & 4 & $85 \%$ & 10 \\
\hline J01MA02 & Ciprofloxacin & Fluoroquinolone antibiotic & 0.8 & $100 \%$ & 5 \\
\hline J01FA09 & Clarithromycin & Macrolide antibiotic & 0.5 & $55 \%$ & 4 \\
\hline J01AA02 & Doxycycline & Tetracycline antibiotic & 0.1 & $80 \%$ & 1 \\
\hline J01FA01 & Erythromycin & Macrolide antibiotic & 1 & $100 \%$ & 4 \\
\hline J01MA06 & Norfloxacin & Fluoroquinolone antibiotic & 0.8 & $90 \%$ & 1 \\
\hline J01MA01 & Ofloxacin & Fluoroquinolone antibiotic & 0.4 & $98 \%$ & 4 \\
\hline J01AA06 & Oxytetracycline & Tetracycline antibiotic & 1 & $35 \%$ & 4 \\
\hline J01EC01 & Sulfamethoxazole & Sulfonamide antibiotic & 0.8 & $100 \%$ & 2 \\
\hline J01EA01 & Trimethoprim & Dihydrofolate reductase inhibitor & 0.4 & $100 \%$ & 1 \\
\hline R01AA08 & Naphazoline & Vasoconstrictor decongestant & 0.4 & $90 \%$ & 1 \\
\hline R01AA05 & Oxymetazoline & Vasoconstrictor decongestant & 0.4 & $35 \%$ & 7 \\
\hline R01AA07 & Xylometazoline & Vasoconstrictor decongestant & 0.8 & $90 \%$ & 11 \\
\hline J05AH02 & Oseltamivir carboxylate & Neuraminidase inhibitor antiviral & 0.2 & $80 \%$ & 2 \\
\hline
\end{tabular}




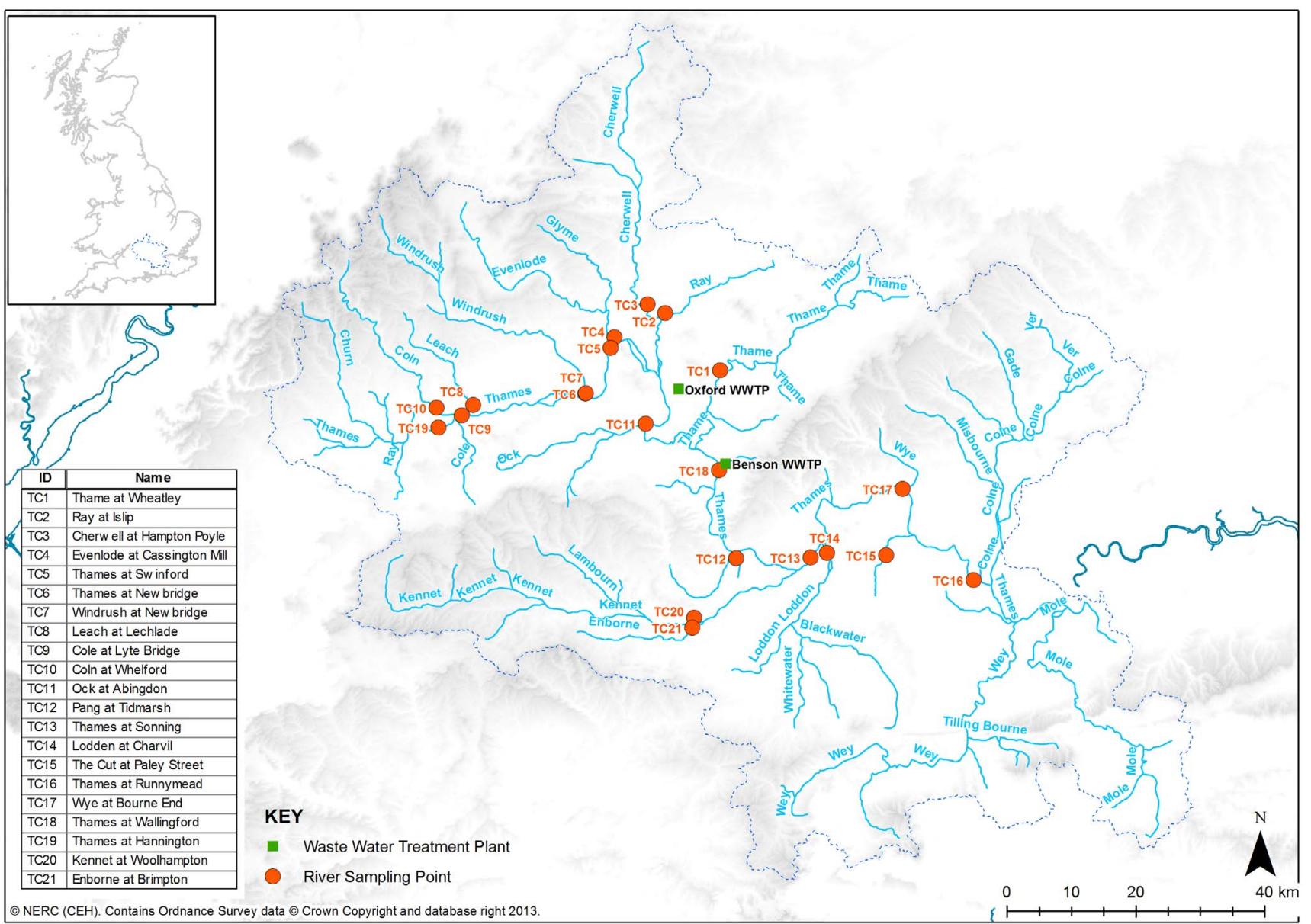

Figure 1. The 21 river sampling locations within the River Thames Catchment (TC) in southern England and the location of the Oxford and Benson WWTPs.

doi:10.1371/journal.pone.0108621.g001

\section{River Flow}

River flow data was acquired from the National River Flow Archive (http://www.ceh.ac.uk/data/nrfa/) for all locations at the closest gauging station to the sampling site (Fig. S2 in File S1). In the case of Loddon at Twyford (TG14) and The Cut at Binfield (TC15), the closest active gauging station was appreciably upstream. In these two cases we employed an infilling method (equipercentile transfer) to estimate the flow at the sampling location, as previously described [23].

\section{Environmental Conditions}

Precipitation data for the $48 \mathrm{~h}$ before the sampling periods was used for the town of Benson, England (Fig. S3 in File S1) [24], which is geographically central to all river sampling locations and reflects the climatic conditions of all the sampling sites for the specific days of the study.

\section{Study analytes}

Oseltamivir is a prodrug, which means it is metabolized in vivo to the active antiviral, oseltamivir carboxylate $(\mathrm{OC})$. Eightypercent of the parent dose is converted to OC, which is excreted and easily recorded in the environment. If only the parent compound was recorded one could not be sure that the drug wasn't flushed down the drain prior to having been consumed or the result of improper disposal from a manufacturing plant [25].
Given that oseltamivir is not manufactured in the Thames catchment, the measures reflected in this study should reflect oseltamivir consumption and not improper disposal. The antibiotics examined in this study were selected as they reflect the drugs most likely to be used during an influenza pandemic $[2,26]$. betaLactams were not included in this study owing to their relatively high propensity to hydrolysis and biodegradation and thus low likelihood for persistence in the environment. The decongestants examined in this study represent a cross section of this class of drug, and does not reflect all or even the majority of decongestants in use in England.

\section{Analytical Technique}

An on-line solid phase liquid extraction/liquid chromatography-tandem mass-spectrometry (SPE/LG-MS/MS) method was used to measure the analyte levels in pre-filtered and acidified $1 \mathrm{~mL}$-samples. This on-line SPE/LC-MS/MS method used has been evaluated and described in detail previously [27]. The online SPE/LG system consisted of a PAL HTC auto sampler (CTC Analytics AG, Zwingen, Switzerland), a Surveyor LC-Pump (Thermo Fisher Scientific, San Jose, CA, USA), an on-line SPE Hypersil GOLD C18 column $(20 \mathrm{~mm} \times 2.1 \mathrm{~mm}$ i.d. $\times 12 \mu \mathrm{m}$, Thermo Fisher Scientific, Waltham, MA, USA), an Accela LC pump (Thermo Fisher Scientific, San Jose, CA, USA), and a Hypersil GOLD G18 column $(50 \mathrm{~mm} \times 2.1 \mathrm{~mm}$ i.d. $\times 3 \mu \mathrm{m}$ particles, Thermo Fisher Scientific, San Jose, CA, USA) with a 
guard C18 column $(2 \mathrm{~mm} \times 2 \mathrm{~mm}$ i.d. $\times 3 \mu \mathrm{m}$ particles, Thermo Fisher Scientific, San Jose, CA, USA). The liquid chromatography system was coupled to a heated electrospray ionization (HESI) source and a Quantum Ultra triple quadrupole mass spectrometer made by Thermo Fisher Scientific (Waltham, MA). The MS/MS parameters used are described in Table S3 in File S1. The following internal standards were obtained from Cambridge Isotope Laboratories (Andover, MA, USA): ${ }^{13} \mathrm{C}_{2}$-Trimethoprim $\left({ }^{13} \mathrm{C}_{2}\right.$-TRI) (99\%), ${ }^{13} \mathrm{C}_{3} 15 \mathrm{~N}$-Ciprofloxacin $\left({ }^{13} \mathrm{C}_{3}\right.$-CIP) (99\%), ${ }^{13} \mathrm{C}_{2}$-Erythromycin $\left({ }^{13} \mathrm{C}_{2}\right.$-ERY $)$ and ${ }^{13} \mathrm{C}_{6}$-Sulphamethoxazole $\left({ }^{13} \mathrm{C}_{6}\right.$-SUL). Oseltamivir carboxylate labeled with deuterium (OCD3) (RO0604802-004; lot: 511-001-2197/4) was obtained from Roche (F. Hoffmann-La Roche Ltd., Basel, Switzerland).

\section{Fate in the WWTPs and the Thames River Catchment-Calculating WWTP and River Load and Percent Loss in WWTP}

Pharmaceutical concentrations were converted to mass loading using hourly WWTP (Fig. S1 in File S1) and river flows for the sampling period. Percent loss of analytes between WWTP influent and effluent as a result of biodegradation and sorption was calculated from the change in 24-h load of each analyte between the two sampling locations. As the influent and effluent samples were acquired simultaneously, the calculated 'percent loss' assumes negligible change in drug use between the Monday and Tuesday during which the samples were acquired and a negligible change in hydraulic retention time. Resulting from such assumptions, the interpretations of the recalcitrance of analytes were considered with caution.

\section{Wastewater Epidemiology-Forward-Calculating Environmental Concentrations of Antibiotics from Prescription Statistics}

The National Health Service Business Services Authority (NHS BSA) annual antibiotic prescriptions for England [28] was used for estimating 'background' pharmaceutical use for the population residing within the two study WWTP catchments in 2009. NHS BSA data are resolved at the national level and reflect annual prescription rates (Table S1 in File S1). More spatially resolved data was acquired from the four Primary Care Trust (PCT) [29] hospitals and clinics serving the Oxford and Benson WWTP catchments, however, this level of detail was only available from November 2011. To assess the value of this data as a proxy for 'background' antibiotic use in November, we examined total antibacterial use in general practice in England since 2007. There was a $<1 \%$ change in total antibiotic prescriptions per year with the exception of penicillin where an increase of approximately $5 \%$ was seen between 2007-2011 [28]. As penicillins were not monitored in this study, we argue that the November 2011 data might serve as an adequate proxy for 'background' antibiotics prescribed during the study period. A large fluctuation from this 'background' usage might be indicative of pandemic-linked usage.

The National Pandemic Flu Service (NPFS) [30] recorded approximately 66,218 courses of Oseltamivir dispensed in Week 43 in 2009, representing $0.13 \%$ of the population of England, and $6 \%$ of all antivirals dispensed during the pandemic [30]. The national peak for the autumnal wave of the influenza pandemic was 3 weeks prior to the WWTP sampling on 10-11 November [30]. The antiviral prescription rate did not rapidly decline after the peak (see Fig. 15 in [30]), suggesting that the peak antiviral prescription rate of $0.13 \%$ might be a good proxy for antiviral use during the sampling period. The standard adult Oseltamivir dosing regime was assumed: $0.075 \mathrm{~g}$ per dose, consumed twice per day $(0.150 \mathrm{~g} / \mathrm{d})$.

An additional dataset produced by the HPA's QSurveillance National Syndromic Surveillance System [31], was examined for estimating Oseltamivir prescription rates. The HPA dataset reports 54.2 people per 100,000 with influenza-like illness (ILI) in the Oxfordshire PCT during the week of WWTP sampling (i.e., Week 46), which was used for modelling purposes. However, the ILI reporting rate declined during November from Week 46 to Week 49, which reached as low as 33 per 100,000 [31].

We provide a general model for calculating the concentration of pharmaceuticals $(\mathrm{ng} / \mathrm{L})$ in wastewater influent $\left(\mathrm{C}_{\mathrm{w}}\right)$ using the different data sources discussed above:

$$
C_{w}=\left(\frac{M \cdot E \cdot F}{P \cdot L}\right) \cdot 10^{9}
$$

where the product of the population of each WWTP catchment $(\mathrm{P})$ and the volume of wastewater per person $(L ; 230 \mathrm{~L} /$ capita/d [2]) was divided into the product of the mass of prescriptions $(M)$ in grams acquired from Average Daily Quantity (ADQ) conversions (Table 1 and S1) [32], mass of parent compound excreted in its parent form $(E)$ in grams, and correction factor $(F)$ for adjusting for when the population served by a PCT is served by more than one WWTP.

When deriving the mass of drug prescribed using NHS BSA statistics, $M=M_{a}+M_{s}$, where $\mathrm{M}_{\mathrm{a}}$ was the annual mass $(\mathrm{g})$ of pharmaceutical prescribed (Table $\mathrm{S} 1$ in File $\mathrm{S} 1$ ) and $\mathrm{M}_{\mathrm{s}}$ reflected the additional mass of drug used $(\mathrm{g})$ in the winter in excess of the average monthly usage (Table $\mathrm{Sl}$ in File S1). Hence, $M_{s}=\left(M_{a} \times 0.09375\right)$, where 0.9375 is the additional fraction of drug used in the winter as compared to the annual mean (i.e., $\mathrm{M}_{\mathrm{a}}$ / 12). This adjustment was performed because it is known that the mean variation in antibiotic consumption between the summer and winter period in the UK was approximately $18.75 \%$ in 2005 [33]. Hence, the annual prescription rate provided by the NHS BSA was increased by $9.375 \%$ from the annual mean prescription rate (i.e., reflecting $50 \%$ of the total seasonal variability between summer and winter). Differences in pharmacokinetics were accounted for using factor $E$, which reflects the fraction of parent chemical excreted into wastewater (Table 1) [4].

The patient population of the PCT serving Benson is served by two different WWTPs at Benson and Cholsey. This difference between the population served by a PCT and the WWTP catchment were accounted for by factor $F$, where $F=0.389$, resulting from the ratio of the population served by the Benson WWTP (6230) to the patient population of the local PCT $(16,000)$. However, $F=1$ for the Oxford WWTP as it was assumed that the populations served by the PCT in Oxford all fed into the Oxford WWTP. Lastly, $F=1$ for all NHSBSA statistics, as the NHSBSA dataset used a national average prescription rate and was not stratified to the local level.

Notably, trimethoprim and sulfamethoxazole are routinely dispensed as a mixture, co-trimoxazole. Use of these drugs was calculated assuming one ADQ of co-trimoxazole contained $0.16 \mathrm{~g}$ of trimethoprim and $0.8 \mathrm{~g}$ of sulfamethoxazole.

All raw data has been made freely available at http://doi.org/ $10 / \mathrm{t} 2 \mathrm{x}$.

\section{Results}

PharmaceuticalFate in Benson and Oxford WWTPs

Antiviral in Benson WWTP. The concentration of OG in the influent on 10-11 November, 2009, ranged from <limit of 


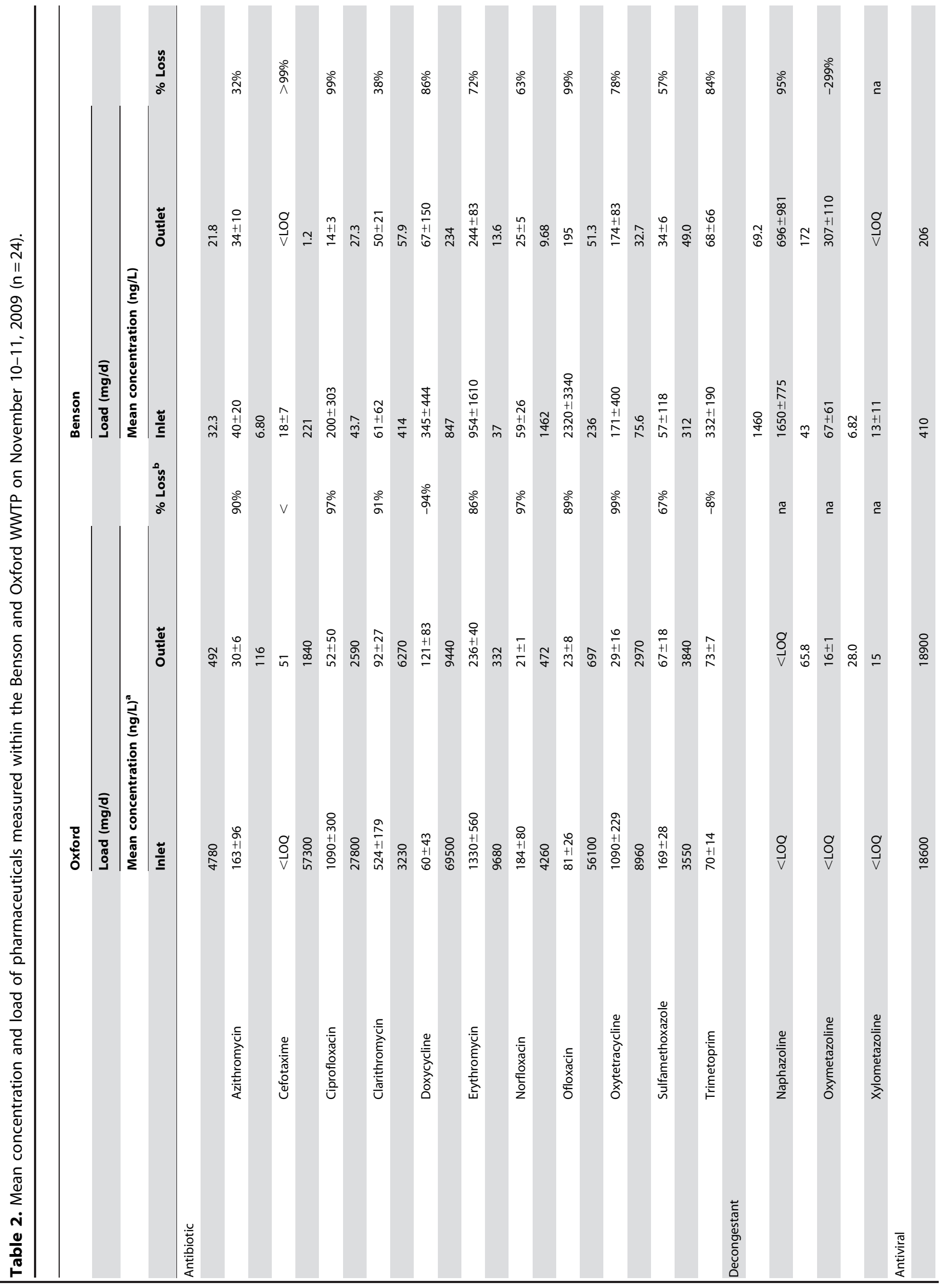




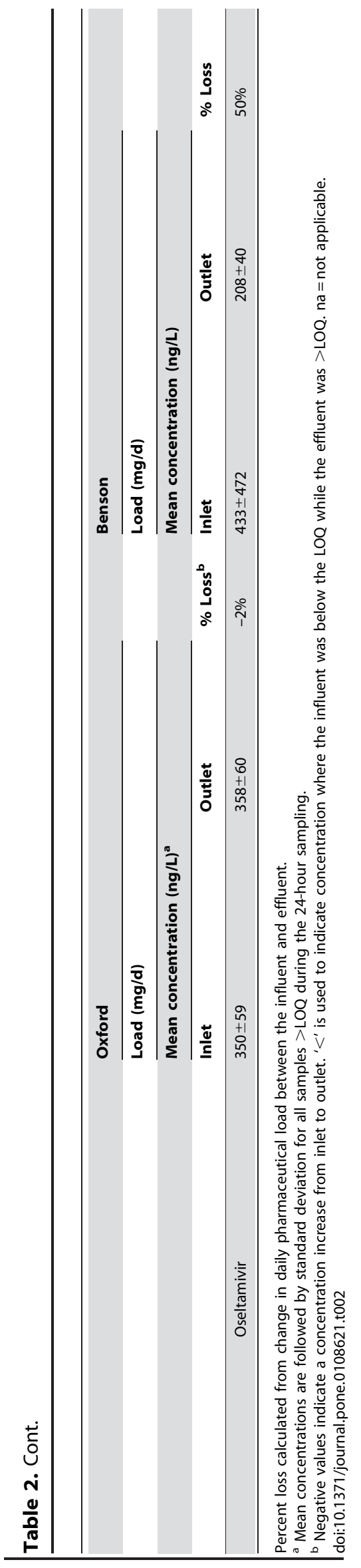

quantification (LOQ; 1-11 ng/L, see Table 1) to $2070 \mathrm{ng} / \mathrm{L}$ (Table 2), with 18 of the 24 measures above the LOQ(Fig. S4 in File S1). The mean hourly concentration (for samples >LOQ), was $433 \pm 472 \mathrm{ng} / \mathrm{L}$. The $24-\mathrm{h}$ load was $410 \mathrm{mg} / \mathrm{d}$, reaching a maximum load of $133 \mathrm{mg} / \mathrm{h}$ at the 18:00 sampling point, equating to $66 \mu \mathrm{g} \mathrm{OC/capita/d}$.

The concentration of $\mathrm{OC}$ in the effluent ranged from $<$ LOQ to $287 \mathrm{ng} / \mathrm{L}$, with 21 of the 24 measures above the LOQ. The mean hourly concentration (for samples >LOQ), was $208 \pm 40 \mathrm{ng} / \mathrm{L}$. The 24-h load was $206 \mathrm{mg} / \mathrm{d}$, reaching a maximum of $16.9 \mathrm{mg} / \mathrm{h}$ at the 9:00 sampling point. The change in load from the influent to the effluent was $204 \mathrm{mg} / \mathrm{d}$, a reduction of $50 \%$.

Antiviral in Oxford WWTP. The concentration of OG in the influent on 10-11 November, 2009, ranged from 257 to $550 \mathrm{ng} / \mathrm{L}$ (Table 2), with all measures above the LOQ. The mean hourly concentration was $350 \pm 59 \mathrm{ng} / \mathrm{L}$. The $24-\mathrm{h}$ load was $18,600 \mathrm{mg} / \mathrm{d}$, equating to $89 \mu \mathrm{g}$ OC/capita/d reaching a maximum load of $1,330 \mathrm{mg} / \mathrm{h}$ at the 10:00 sampling point.

The concentration of OC in the effluent ranged from 474 to $1,130 \mathrm{ng} / \mathrm{L}$, with all measures above the LOQ. The mean hourly concentration was $358 \pm 60 \mathrm{ng} / \mathrm{L}$. The $24-\mathrm{h}$ load in the effluent was $18,900 \mathrm{mg} / \mathrm{d}$, reaching a maximum of $1130 \mathrm{mg} / \mathrm{h}$ at the $8: 00$ sampling point. The change in 24-h load from the influent to the effluent was $-300 \mathrm{mg} / \mathrm{d}$, a trivial increase of $2 \%$ in the effluent, suggestive of a fully conservative chemical.

Antibiotics in Benson WWTP. Erythromycin showed the highest average antibiotic concentration in the influent, $954 \mathrm{ng} / \mathrm{L}$ ( $\mathrm{n}=17,134 \mu \mathrm{g} /$ capita/d) and effluent $244 \mathrm{ng} / \mathrm{L}(\mathrm{n}=20,37 \mu \mathrm{g} /$ capita/d; Table 2) and reached as high in concentration as $6,870 \mathrm{ng} / \mathrm{L}$ in the influent. Three antibiotics, at least once in the 24-h sampling, exceeded the average inlet concentration of erythromycin: ofloxacin $(\max =11,000 \mathrm{ng} / \mathrm{L}, 235 \mu \mathrm{g} / \mathrm{cap} / \mathrm{d}$, $\mathrm{n}=12)$, doxycycline $(\max =1,550 \mathrm{ng} / \mathrm{L}, 66 \mu \mathrm{g} / \mathrm{cap} / \mathrm{d}, \mathrm{n}=23)$ and oxytetracycline $(\max =1,700 \mathrm{ng} / \mathrm{L}, 38 \mu \mathrm{g} / \mathrm{cap} / \mathrm{d}, \mathrm{n}=20)$. Notably, ciprofloxacin was recorded as high as $917 \mathrm{ng} / \mathrm{L}(35 \mu \mathrm{g} /$ $\mathrm{cap} / \mathrm{d}, \mathrm{n}=16)$ and trimethoprim as high as $780 \mathrm{ng} / \mathrm{L}(50 \mu \mathrm{g} / \mathrm{cap} /$ $\mathrm{d}, \mathrm{n}=21)$.

With the exception of cefotaxime, which was found in only 7 of 24 samples from Benson influent, all antibiotics were found in at least half of the 24 samples, with 6 antibiotics found at each of the 24 hourly measurements (Fig. S4 in File S1).

The load of each of the 11 antibiotics in the Benson WWTP effluent was reduced by $32 \%$ to a maximum of $99 \%+$ after treatment (Table 2), the most persistent being azithromycin $(32 \%$ loss, $\mathrm{n}=18$ and $\mathrm{n}=15$ for inlet and outlet, respectively) and clarithromycin (38\% loss, $n=13$ and $n=11$, respectively).

Antibiotics in Oxford WWTP. Erythromycin showed the highest average antibiotic concentration in the influent $(1,330 \mathrm{ng} /$ $\mathrm{L}, 341 \mu \mathrm{g} / \mathrm{cap} / \mathrm{d}, \mathrm{n}=24$ ) and reached a maximum concentration of 2,930 ng/L (Table 2). Two other antibiotics recorded mean concentrations in the influent above $1,000 \mathrm{ng} / \mathrm{L}$, oxytetracycline $(1,090 \mathrm{ng} / \mathrm{L}, 275 \mu \mathrm{g} / \mathrm{cap} / \mathrm{d}, \mathrm{n}=24)$ and ciprofloxacin $(1,090 \mathrm{ng} /$ $\mathrm{L}, 281 \mu \mathrm{g} / \mathrm{cap} / \mathrm{d}, \mathrm{n}=24)$. Two antibiotics achieved maximum concentration that exceeded the average inlet concentration set by erythromycin: oxytetracycline $(1,430 \mathrm{ng} / \mathrm{L})$ and ciprofloxacin (1,530 ng/L; Table 2). Notably, clarithromycin achieved a maximum of $980 \mathrm{ng} / \mathrm{L}(136 \mu \mathrm{g} / \mathrm{cap} / \mathrm{d})$, much higher than the maximum in Benson (243 ng/L, $7 \mu \mathrm{g} / \mathrm{cap} / \mathrm{d})$.

With the exception of cefotaxime (0/24), azithromycin (13/24) and trimethoprim (23/24), all antibiotics were found at each of the 24 hourly measurements from the Oxford influent.

The antibiotic load in the Oxford WWTP effluent was reduced by $67 \%$ to $<$ LOD after treatment for many antibiotics (Table 2), however, unlike Benson, several demonstrated persistence and 


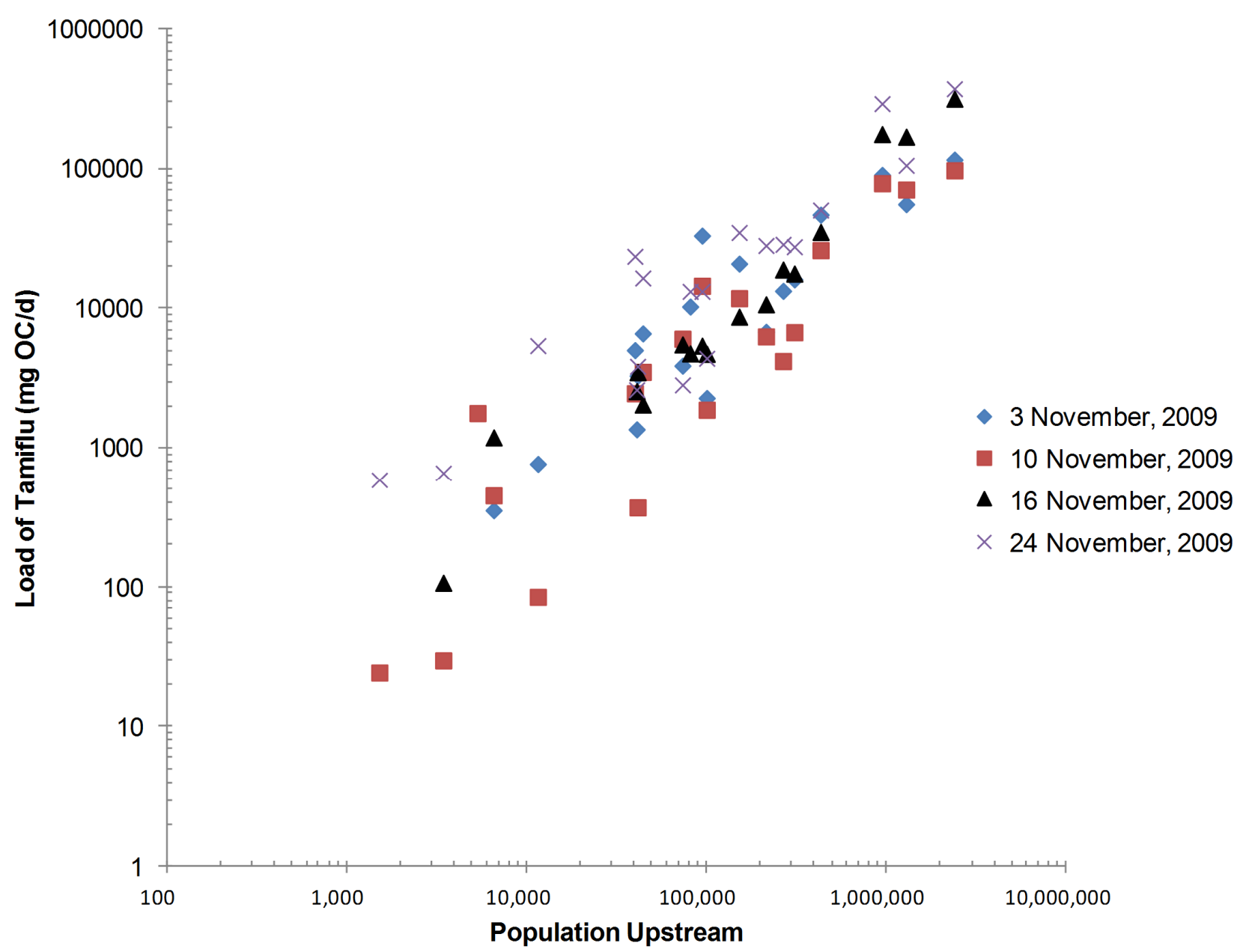

Figure 2. Correlation between population upstream and daily load of $\mathrm{OC}$ in river $(\mathrm{mg} \mathrm{OC} / \mathrm{d})$ for each of the four sampling points: November 3 (diamond), November 10 (square), November 16 (triangle) and November 24 ('x'), 2009. doi:10.1371/journal.pone.0108621.g002

concentration, including: cefotaxime (increase from $<\mathrm{LOQ}$ to $51 \mathrm{ng} / \mathrm{L}(\mathrm{n}=1)$ for inlet and outlet, respectively), doxycycline (increase by $94 \%$ from $3230 \mathrm{ng} / \mathrm{L}(\mathrm{n}=24)$ to $6270 \mathrm{ng} / \mathrm{L}(\mathrm{n}=24)$, respectively) and trimethoprim (increase by $8 \%$ from $70 \mathrm{ng} / \mathrm{L}$ ( $\mathrm{n}=24)$ to $73 \mathrm{ng} / \mathrm{L}(\mathrm{n}=24)$, respectively).

Decongestants in Benson WWTP. Approximately $1.56 \mathrm{~g} / \mathrm{d}$ of decongestant was quantified in the Benson WWTP influent $(0.25 \mathrm{mg} / \mathrm{capita} / \mathrm{d}), 97 \%$ of which was a single decongestant, naphazoline. The most frequently quantified decongestant in the influent was naphazoline $(\mathrm{n}=19)$, however, oxymetazoline was the most frequently found decongestant in the effluent $(n=18$; Table 2). Oxymetazoline achieved a mean influent and effluent concentration of $67 \mathrm{ng} / \mathrm{L}$ and $307 \mathrm{ng} / \mathrm{L}$, respectively. Unlike oxymetazoline, naphazoline averaged higher concentrations in the influent $(1,650 \mathrm{ng} / \mathrm{L})$ than the effluent $(696 \mathrm{ng} / \mathrm{L})$. Naphazoline reached a higher maximum concentration in the influent and effluent $(3,070 \mathrm{ng} / \mathrm{L}, 1,390 \mathrm{ng} / \mathrm{L}$, respectively) than oxymetazoline $(177 \mathrm{ng} / \mathrm{L}, 440 \mathrm{ng} / \mathrm{L}$, respectively). The influent load $(1,460 \mathrm{mg} / \mathrm{d})$ for naphazoline, was reduced by $95 \%$ as compared to the effluent $(69 \mathrm{mg} / \mathrm{d}, \mathrm{n}=2)$, indicating it is unlikely to be a persistent environmental pollutant. Xylometazoline averaged concentrations only marginally above the LOQ $(11 \mathrm{ng} / \mathrm{L})$ in the influent $(13 \mathrm{ng} / \mathrm{L} ; 7 \mathrm{mg} / \mathrm{d}, \mathrm{n}=10)$, and was $<\mathrm{LOQ}$ in all of the effluent samples.
Decongestants in Oxford WWTP. Unlike at Benson WWTP, no decongestant was found from the Oxford WWTP influent, within the limits of quantification. However, decongestants were quantified from the Oxford WWTP effluent during the hours 2:00 and 3:00-notably the time when the Oxford WWTP influent flow was at its minimum (Fig. S1 in File S1); these were xylometazoline $(15 \mathrm{ng} / \mathrm{L}, 28 \mathrm{mg} / \mathrm{d}, \mathrm{n}=1)$ and oxymetazoline $(16 \mathrm{ng} / \mathrm{L}, 66 \mathrm{mg} / \mathrm{d}, \mathrm{n}=2)$, the latter of which indicated a propensity for concentration within the Benson WWTP, while the former did not.

\section{Pharmaceutical Occurrence in the Thames River Catchment}

Antiviral. OC was the most frequently measured analyte with concentrations $>$ LOQ at $73 \%$ of the river sampling locations during the month of November, 2009. The mean concentration of OC across the Thames catchment was 65, 61, 33 and $33 \mathrm{ng} / \mathrm{L}$ for November 3, 10, 16, and 24, respectively (Fig. 2 \& 3). A maximum OC concentration of $193 \mathrm{ng} / \mathrm{L}$ was recorded at The Cut at Paley Street (T15) on Nov 10 (Figs. 3, S5b in File S1), a site known to be among the more severely impacted by sewage [22] with relatively low dilution per capita (Fig. S2 in File S1). The mean load of OC across all 21 sites was 24, 18, 46 and $55 \mathrm{~g}$ OC/d for November 3, 10, 16 and 24, respectively, with a maximum load on November 24 at the Thames at Runnymead (TC16) site, the location with the 


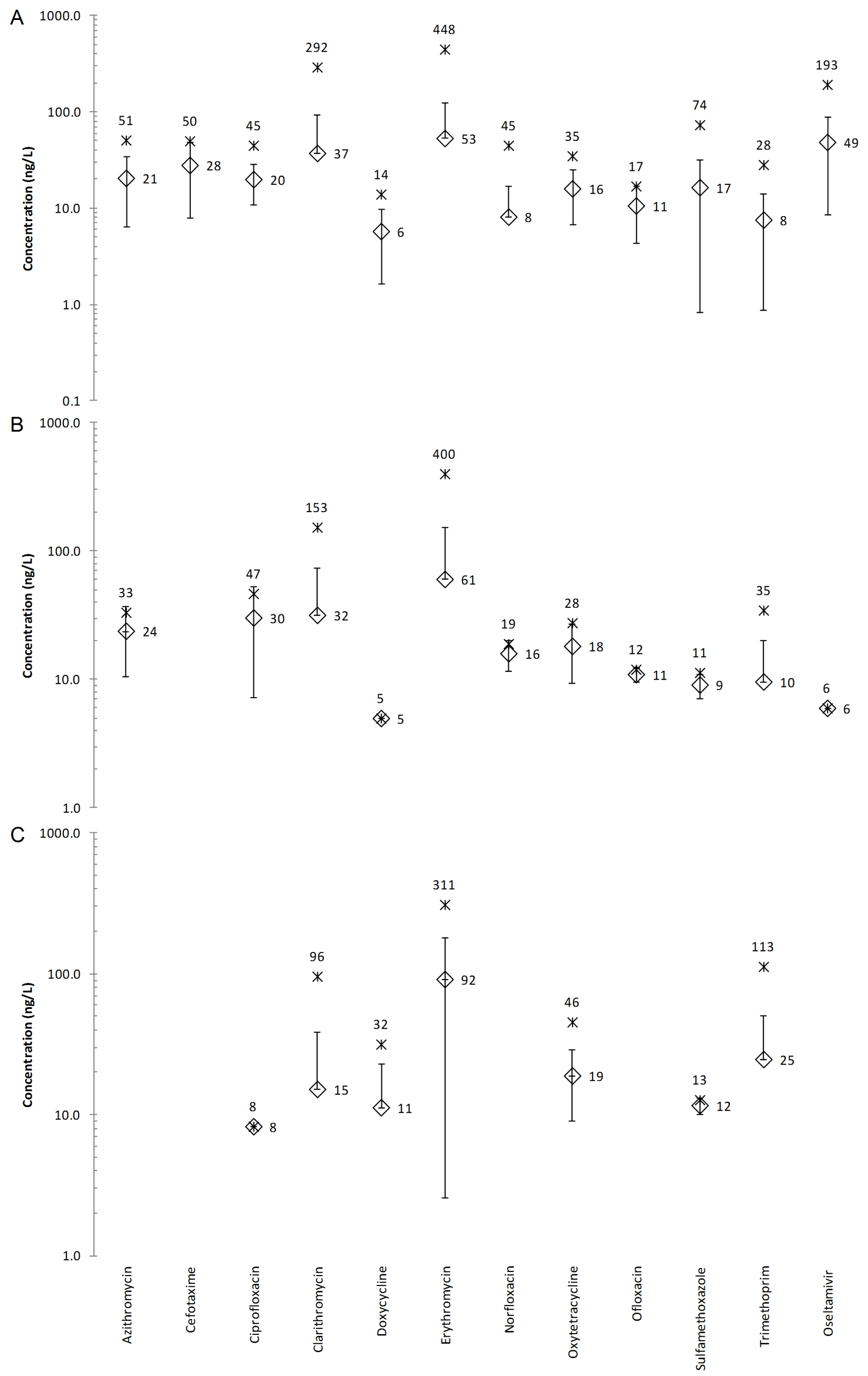


Figure 3. Mean (diamond; with standard deviation (upper and lower error bar)) and maximum (asterisk) concentration (ng/L) of pharmaceuticals across the 21 River Thames locations during (A) the four sampling occasions in November 2009 (intra-pandemic, $\mathbf{n = 8 4 ) ; ~ ( B ) ~} 15$ March, 2010 (late-pandemic. $\mathbf{n}=21$ ); and (C) 11 May, 2011 (inter-pandemic, $\mathbf{n}=21$ ). 'Maximum' data label is above asterisk, while 'mean' data label is to the right of the diamond. Decongestants were omitted as none were found $>$ LOQ. doi:10.1371/journal.pone.0108621.g003

highest upstream population (2.3 million; Fig. S2 in File S1). A strong positive correlation $\left(\mathrm{R}^{2}=0.82\right.$ to 0.96$)$ between the population upstream of a sampling location and the load of OC further confirms this expected relationship (Fig. 2). The Thames at Runnymead (TC16; Fig. 1), recorded 117, 98, 319, and $377 \mathrm{~g}$ OC/d $(49,41,134,158 \mu \mathrm{g} /$ capita/d, respectively) for the same time points in November (Fig. 4). With only a few exceptions, the per capita usage at TC16 (the most downstream sampling point on the River Thames) was consistent with estimates generated from many of the upstream sampling sites (Fig. 4), indicating that OC was relatively conserved within the river environment.

OC was not found in any river sampling location in March 2010 or May 2011 except for one location in March, TC17 (River Wye at Bourne End; Fig. S5e, f in File S1). In this location a concentration of $6 \mathrm{ng} / \mathrm{L}$ was recorded with an estimated load/d of $622 \mathrm{mg} / \mathrm{d}$ or $8.48 \mu \mathrm{g} / \mathrm{capita} / \mathrm{d}$, approximately 13\% that achieved during the month of November $(63 \mu \mathrm{g} / \mathrm{capita} / \mathrm{d})$ at this site.

Antibiotics. The concentration range for antibiotics largely fell within the low-ng/L range (17-74 ng/L; Figs. 3, S5a-e in File $\mathrm{S} 1)$, with the exception of clarithromycin $(\max =292 \mathrm{ng} / \mathrm{L})$ and erythromycin $(\max =448 \mathrm{ng} / \mathrm{L})$, at TC15 and TC14, respectively. Much like OC, the load of antibiotics across all time points was positively correlated with the number of people upstream of the sampling location. Erythromycin was by far the most frequently recorded antibiotic, $>\mathrm{LOQ}$ in $87 \%$ of samples, equally as abundant as OC (Fig. 3 \& 5). Clarithromycin and trimethoprim were recorded in approximately $50 \%$ of samples. Ciprofloxacin and norfloxacin were measured in 39 and $33 \%$ of samples. Sulfamethoxazole was found in $30 \%$ of the river samples, while they were recorded in $79-100 \%$ of WWTP inlet and $68-83 \%$ of outlet samples. Similarly, doxycycline was frequently found in WWTP inlet and outlet samples $(96-100 \%$ and $71-100 \%$, respectively), but only measured $>$ LOQ in $18 \%$ of river samples.

The mean load of antibiotics $(\mu \mathrm{g})$ per capita (upstream population) per day was calculated for each of the analytes across the four November sampling times. Estimates range between $84 \mu \mathrm{g} / \mathrm{cap} / \mathrm{d}$ for TC6, where only 4 antibiotics were recorded (ciprofloxacin, clarithromycin, erythromycin and norfloxacin), to
$893 \mu \mathrm{g} / \mathrm{cap} / \mathrm{d}$ for TC4 where six antibiotics were recorded. Despite all 11 antibiotics being recorded at TG15, it was among the lower yielding sites at $119 \mu \mathrm{g} / \mathrm{cap} / \mathrm{d}$. The low levels of antibiotics per person in The Cut at Paley Street could be down to the fact that The Cut is impacted by a very small number (3) of relatively large WWTPs (Bracknell $=77600$ person equivalents $(\mathrm{PE})$; Ascot $=26000 \mathrm{PE}$; White Waltham $=5150 \mathrm{PE})$, and therefore all the effluent has a relatively good level of treatment. There are no small WWTPs in this catchment, unlike all the other sites. The Cut was also one of only three sites to record cefotaxime. The sites that reflect the highest population upstream, TC18, TC13 and TC16, yielded estimates of 633, 199 and $263 \mu \mathrm{g} / \mathrm{cap} / \mathrm{d}$ and recorded 8 or 9 of the 11 antibiotics.

Late-pandemic/Inter-pandemic period. Fewer antibiotics were found at the late-pandemic period (mean 2.6 \pm 2.6 ; March

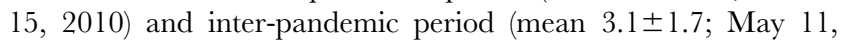

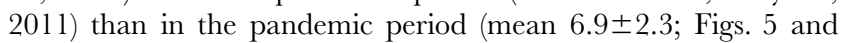
$\mathrm{S} 5 \mathrm{a}-\mathrm{e}$ in File S1). The load of antibiotic found at each river location during the inter-pandemic period (May 2011) was less than that found during the pandemic (Figs. S5a-e in File S1). In all but three cases (TC11, TC15 and TC17), the same was true for the late-pandemic sampling points. Notably during the latepandemic period, erythromycin was found at a concentration of $400 \mathrm{ng} / \mathrm{L}$ in TC15, a highly sewage impacted site; a site that achieved nearly $750 \mathrm{ng} / \mathrm{L}$ in total antibiotics. The high erythromycin level was again found in the inter-pandemic sampling (May, 2011) at TC17, achieving $311 \mathrm{ng} / \mathrm{L}$ (Fig. S5e in File S1). At site TC15, the level of trimethoprim was also exceptionally high $(113 \mathrm{ng} / \mathrm{L})$, far exceeding the maximum concentration found during the pandemic (November, 2009; $28 \mathrm{ng} / \mathrm{L}$ ). It is unclear whether these levels are the result of a local outbreak, normal fluctuation, or evidence of improper disposal.

Decongestants. Naphazoline, the most frequently found decongestant in the Benson WWTP was not found in the river samples. Oxymetazoline in the Benson WWTP effluent, along with xylometazoline, was also not found in the river samples. Decongestants were also not found in the river samples collected during the late-pandemic or the inter-pandemic period.

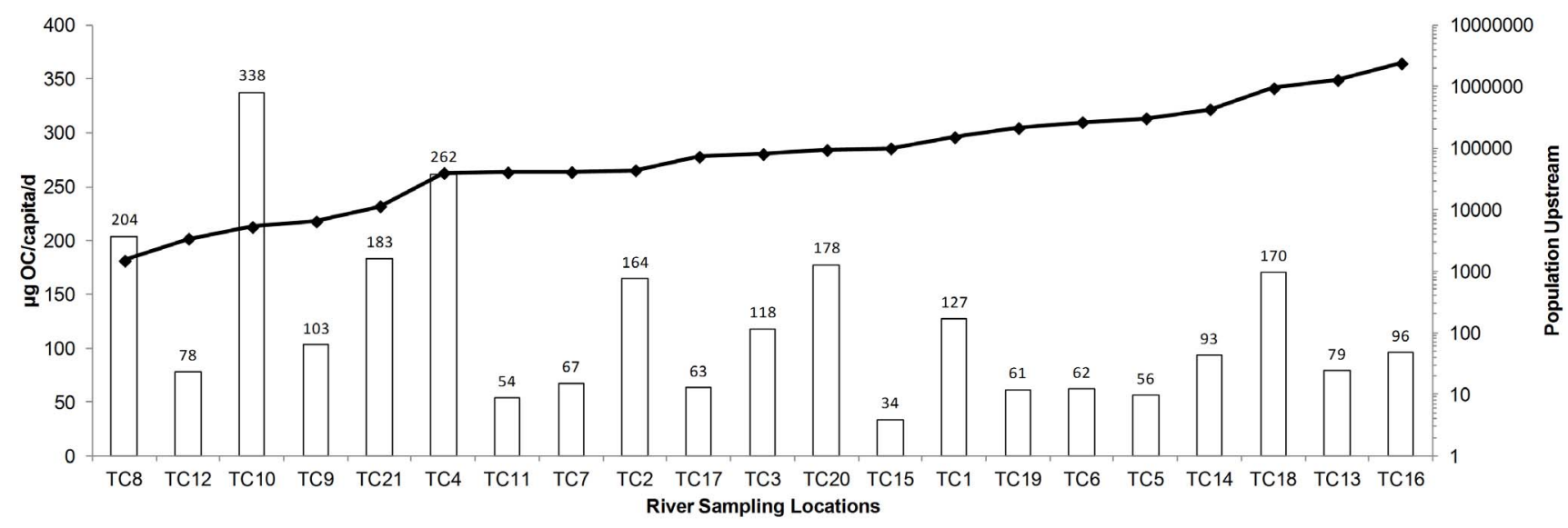

Figure 4. Mean load of oseltamivir (OC) per capita per day ( $\mu \mathrm{g} / \mathrm{cap} / \mathrm{d})$ across all river sampling locations throughout November 2009 (intra-pandemic period). Triangles indicate the population upstream at that location. doi:10.1371/journal.pone.0108621.g004 


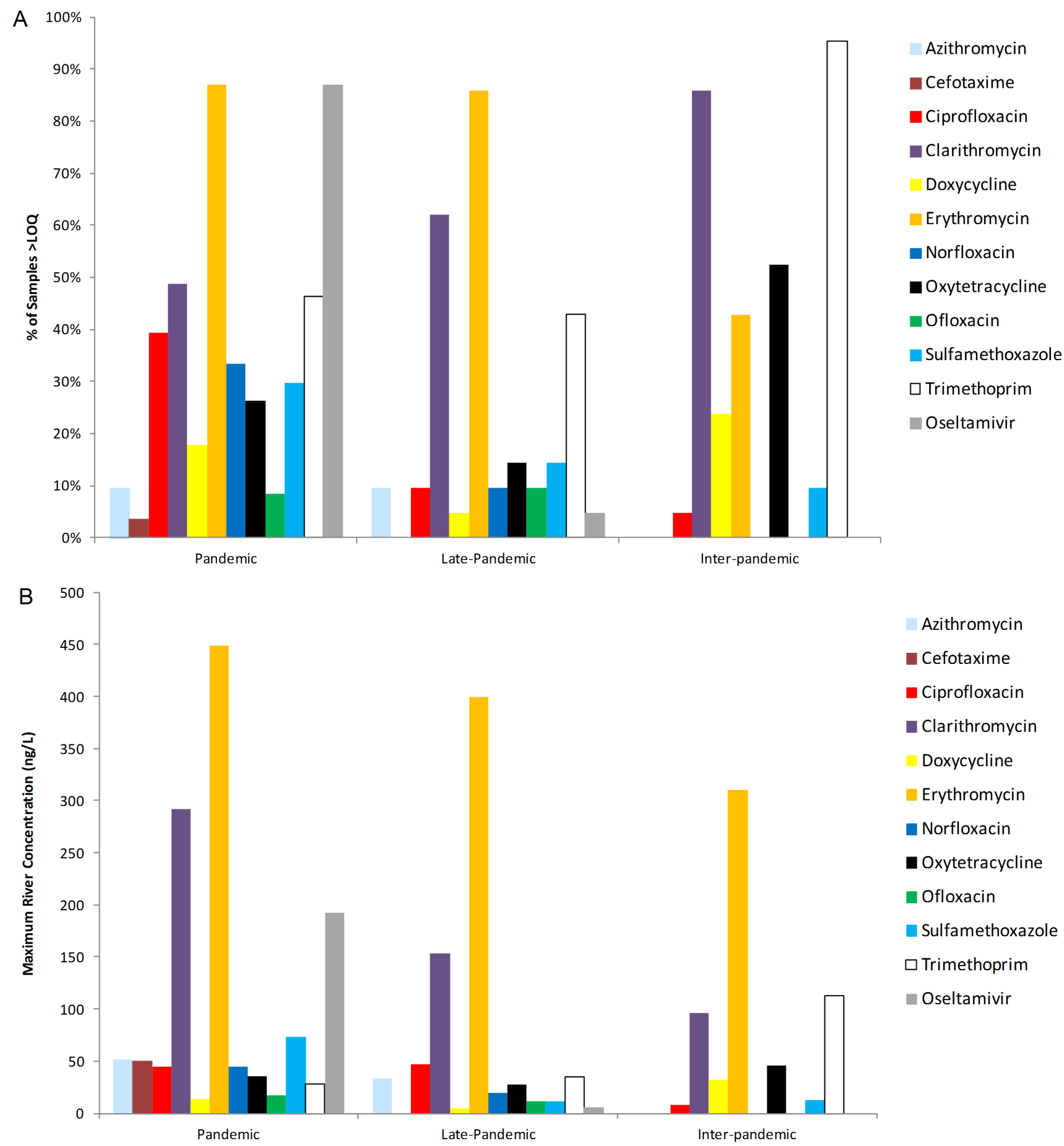

Figure 5. Comparison of pharmaceutical (A) abundance (\% of samples above the limit of quantification (LOQ)) and (B) the maximum river concentration ( $\mathrm{ng} / \mathrm{L}$ ) during the pandemic period (November, 2009), late pandemic period (March 2010) and the inter-pandemic period (May 2011). doi:10.1371/journal.pone.0108621.g005

\section{Drug Use by Wastewater Epidemiology}

Estimation of oseltamivir compliance, i.e., use of the drug as prescribed, was approximately $45-60 \%$ as previously reported [34]. Estimation of antibiotic use were derived from government statistics (mg/excreted/d; Table 3). Overall, neither of the government statistics (PCT or NHS BSA) were accurate predictors of MELs.

\section{Discussion}

Pharmaceutical Fate and Occurrence in Oxford and Benson WWTPs, and the Thames River Catchment

Antiviral. Mean concentrations of OC in the WWTP influent (350, $443 \mathrm{ng} / \mathrm{L})$ and effluent $(208,358 \mathrm{ng} / \mathrm{L})$ were consistent with the range previously reported in the literature $11-1450 \mathrm{ng} / \mathrm{L}$ (Table S2 in File S1) [1,25,35-39]. The maximum concentration 


\begin{tabular}{|c|c|c|c|c|c|c|}
\hline & \multicolumn{3}{|c|}{ Benson } & \multicolumn{3}{|c|}{ Oxford } \\
\hline & \multicolumn{2}{|c|}{$\mathrm{mg} / \mathrm{excreted} / \mathrm{d}^{\mathrm{a}}$} & \multirow{2}{*}{$\frac{\mathrm{mg} / \mathrm{d}}{\mathrm{MEL}^{\mathrm{d}}}$} & \multicolumn{2}{|c|}{$\mathrm{mg} / \mathrm{excreted} / \mathrm{d}^{\mathrm{a}}$} & \multirow{2}{*}{$\begin{array}{l}\mathrm{mg} / \mathrm{d} \\
\mathrm{MEL}\end{array}$} \\
\hline & $\mathbf{P C T}^{\mathbf{b}}$ & NHS BSAc & & $\overline{\text { PCT }}$ & NHS BSA & \\
\hline Azithromycin & 55.2 & 75.7 & 32.3 & 652 & 6493 & 4782 \\
\hline Cefotaxime & na & na & 7.00 & na & na & $<\mathrm{LOQ}$ \\
\hline Ciprofloxacin & 389 & 1229 & 221 & 7150 & 105409 & 57258 \\
\hline Clarithromycin & 89.2 & 441 & 43.7 & 2035 & 37810 & 27846 \\
\hline Doxycycline & 54.0 & 34.2 & 414 & 757 & 2933 & 3234 \\
\hline Erythromycin & 1259 & 3920 & 847 & 18833 & 336086 & 69475 \\
\hline Norfloxacin & 0 & 0 & 37 & 0 & 0 & 9677 \\
\hline Ofloxacin & 0 & 6 & 1462 & 26.1 & 479 & 4257 \\
\hline Oxytetracycline & 195 & 187 & 236 & 3080 & 16040 & 56136 \\
\hline Sulfamethoxazole & 51.9 & 103 & 75.6 & 693 & 8799 & 8956 \\
\hline Trimethoprim & 800 & 1120 & 312 & 6693 & 96060 & 3548 \\
\hline
\end{tabular}

a Predicted amount of drug excreted from the daily doses (ADO) of antibiotic consumed during $24-\mathrm{h}$ sampling from Benson and Oxford WWTP influent as per: ${ }^{\mathrm{b}}$ Primary Care Trust (PCT) and ${ }^{c}$ National (NHS BSA) statistics for antibiotic use. ${ }^{d}$ Measured environmental load (MEL) from 24 -hourly wastewater inlet samples (sum of each antibiotic/24 h). No biodegradation other than pharmacokinetics (Table 1) was assumed. na=prescription statistics were unavailable.

doi:10.1371/journal.pone.0108621.t003

found in this study $(2,070 \mathrm{ng} / \mathrm{L}$, Benson influent) was the highest reported in the literature during the pandemic (827 ng/L [35]). The persistence of OC in the Oxford WWTP is consistent with many reports in the literature that document minimal loss of OC in laboratory and field studies [13,35,37,38,40]. However, the extent of OC loss seen in the Benson WWTP (approximately $50 \%)$, was well above the range reported for WWTP not using ozonation, but it is consistent with the removal efficiency reported in WWTPs with ozonation in Germany, where elimination of OC was reported to be $59 \%$ [25], and Japan, where loss was between $30-40 \%$ [38].

Given the mild nature of the pandemic, measured environmental concentrations (MECs) of OC (33-62 ng/L) were 2-3 orders of magnitude lower than predicted environmental concentrations (PECs) in this catchment during a severe pandemic, i.e., $\mathrm{R}_{0}>2.0[2,7]$, but is consistent with the lower end of PECs for a mild pandemic within the Thames catchment (27-11,000 ng/L; [2]). As expected, no $\mathrm{OG}$ was found during the inter-pandemic period (May 2011) from either the WWTP effluent or river sampling locations, reinforcing the assumption that Oseltamivir was used in negligible amounts during the inter-pandemic period in the UK (Fig. 5).

Previous studies have demonstrated OC resistance development where influenza-infected mallard ducks had been exposed to water containing OC at concentrations $\geq 1000 \mathrm{ng} / \mathrm{L}[15,18]$, which closely approximates concentrations recorded in Japan $[36,41]$ and within an order of magnitude of many measured concentrations in the literature and this study (Table S2 in File S1). The evidence in this study and the literature further lend support to the likelihood of OC-resistance generation in wildfowl influenza viruses; owing to its significance to human health, this is worthy of additional study.

Antibiotics. In general, the antibiotics were more labile in the Oxford WWTP as compared with Benson, mostly likely due to the fact that Oxford uses activated sludge treatment while Benson relies on a trickling filter to treat wastewater. Fewer different antibiotics were recovered in the river during the late-pandemic
(March 15, 2010) and the inter-pandemic (May 11, 2011) period than in the peak pandemic period (November 2009; Figure 5). However, some antibiotics did not show any appreciable decline in concentration (erythromycin, oxytetracycline and trimethoprim). It is unclear to what extent the persistence of these antibiotics in the river is related to the average river temperatures; it could be expected that higher river temperatures would facilitate the biotransformation of the antibiotics. The water temperature during the March 15, 2010 sampling was the lowest $\left(8.2^{\circ} \mathrm{C}\right)$, followed by the four November sampling points (12.7, 9.7, 9.9 and $10.3^{\circ} \mathrm{C}$ respectively), while the water temperature in May 11,2011 was the highest, $15.6^{\circ} \mathrm{C}$. Evidence for an exponential relationship between the biodegradation rate and temperature suggest the temperature range in this study is likely to be an important variable in explaining the frequency and concentration of analytes recovered in different seasons [42,43].

Decongestants. The detection of decongestants in Oxford WWTP effluent (notably in the lowest flowing period of the day), and not in the influent, suggests a degree of concentration within the WWTP. This is likely due to the relatively high lipophilicity of the decongestants (predicted $\log P$ : naphazoline 3.8, xylometazoline 5.2, and oxymetazoline 4.5; www.chemspider.com). High $\log P$ would facilitate partitioning of the decongestant onto suspended organic matter which is recycled in the Oxford WWTP. Notably, the trickling filter treatment of Benson WWTP also appeared to concentrate oxymetazoline, with negligible change in naphazoline and a significant decline in xylometazoline. Although all the decongestants are found in the WWTPs, they do not appear to persist in rivers, or if they do, they persist in an adsorbed state (i.e., to sediment), which was not measured as part of this study. Future studies will need to examine how representative this study is across a wider range of WWTPs and over a longer period of monitoring. Furthermore, future research should target different environmental matrices to ensure these pharmaceuticals are not accumulating in river sediment. 


\section{Drug Use by Wastewater Epidemiology}

Antiviral. The potential for wastewater epidemiology is highest when studying a recalcitrant, water soluble pollutant. This is one of the major reasons why the wastewater epidemiology approach has so much potential when applied to OC [34]. The physico-chemical benefits of $\mathrm{OC}$ are further enhanced because it is consumed as a prodrug. As such, improperly disposed Oseltamivir would be found in wastewater as the parent compound oseltamivir not OC. Hence, the difference between consumption and improper disposal can be relatively easily illuminated.

Antibiotics. To our knowledge the antibiotics within this study are not provided in a prodrug form, making estimates of their usage susceptible to misinterpretation owing to potential improper disposal. The recalcitrance of antibiotics is known to vary greatly in wastewater $[44,45]$ making it considerably more difficult to accurately predict environmental concentrations, as can been seen in Table 3 . The variability in the recalcitrance of antibiotics in WWTPs and within the same WWTP over time and between differing WWTPs of different size and treatment technologies are likely among the main sources of error in the wastewater epidemiology approach when applied to antibiotics. Typically, the measured environmental load for each antibiotic (Table 3), was lower than the forward-calculated values from PCT or NHS BSA statistics, hence, the projected antibiotic users were frequently over estimated. Efforts to improve the wastewater epidemiology approach for antibiotics will need to address: (a) heterogeneity in the temporal distribution of prescriptions over time; (b) heterogeneity in the spatial distribution of prescriptions (across the UK) over time; (c) heterogeneity in in vivo and environmental stability of the antibiotic, including sewage pipes prior to reaching the WWTP inlet [46]; and (d) variability in compliance rate. It has been shown that the compliance rate for antibiotics can depend on the number of doses per day and age [47-49]. Further consideration should be given to (e) the sample size and sampling method. The relatively low number of pharmaceutical users in the two WWTP catchments, and the Benson WWTP catchment in particular, leaves model estimates of antibiotic users highly susceptible to systematic errors, as previously described [50]. The heterogeneity in the content of wastewater associated with low flush events, typical of low flow periods in the middle of the night, are a major factor influencing variations in analyte recovery over much of the sampling period [51-53]. This higher variability can be witnessed by the higher standard deviation in hourly measures of $\mathrm{OC}$ in Benson $(433 \pm 472 \mathrm{ng} / \mathrm{L})$ as compared to Oxford $(358 \pm 60 \mathrm{ng} / \mathrm{L})$. The Oxford and Benson sewer systems receive flow from a number of pumping stations that contribute to the mixing of discrete flushing events, however, the problems associated with sampling small populations would be more effectively alleviated with more intensive sampling (every 5-15 minutes) [50]. And finally, the wastewater epidemiology approach for antibiotics will likely be highly sensitive to $(\mathrm{f})$ variability in environmental temperatures and precipitation, where low temperatures will likely retard biodegradation and high precipitation will dilute potentially inhibitory levels of drug while also resuspending sediment that can subsequently influence the drug's fate.

Decongestants. The ability to predict decongestant users from measured concentrations in WWTP influent was constrained by the same systematic problems discussed earlier for the antibiotics, but might be further constrained by: 1) their apparent susceptibility to biodegradation; 2) their high rate of nonprescription use (i.e., over-the-counter), thereby hindering the acquisition of spatially and temporally resolved use data to confirm model projections; and 3) their more sporadic use pattern than antibiotics, the latter of which has a typical course of two to four tables per day for 7 to 10 days, whereas decongestants are only used as and when required. Given these many limitations, there was no ability to predict decongestant user numbers from measured environmental concentrations.

\section{Conclusions}

In hindsight, the 2009 influenza $\mathrm{A}(\mathrm{H} 1 \mathrm{~N} 1)$ pdm09a virus generated a relatively small number of fatalities as compared to severe pandemics like the 1918 'Spanish flu', which meant that the medical response was proportionately lower than would have been expected in a moderate or severe influenza pandemic. Hence, the potential negative effects to WWTP operation [13] and the environment proposed to occur in a moderate and severe pandemic $[2,14]$ were not reported. This study provides the first evidence that antibiotic and antiviral use was elevated during the pandemic. Theoretically, the antiviral recorded in the River Thames was of sufficient concentration to select for antiviral resistance in wildfowl [18,54]. However, it remains to be demonstrated whether this had occurred.

There remains a great deal of uncertainty with regard to pharmaceutical use patterns during a pandemic, as a result of poor adherence to prescribed drugs [34] and the widespread use of over-the-counter medications. The focus on Oseltamivir here and in the literature is unlikely to reflect antiviral practices beyond 2020 owing to an increasing number of influenza antivirals in the pipeline [55-57]. However, for the time being, Oseltamivir remains one of the few antivirals within national stockpiles and as such, remains an important medical tool and potentially significant environmental pollutant [58]. Future influenza pandemics might, in fact, employ a combination therapy of two or more antivirals in an effort to combat resistance $[59,60]$.

Opportunities to ground truth model predictions for 'black swan events' such as influenza pandemics are, by definition, very rare (every 30 years), making this study conducted during the last influenza pandemic a unique window onto public health practice, human behavior, and drug adherence in the UK. It represents the first study to measure antibiotics and decongestants in influent and effluent and receiving rivers during a public health emergency, thereby establishing a baseline from which future modeling and risk assessments can be built in preparation for more severe public health emergencies.

\section{Supporting Information}

File S1 Figure S1. Hourly total pharmaceutical load in Benson (A) and Oxford (B) WWTP inlet, for antibiotics (diamond), oseltamivir carboxylate (square), and decongestants (triangle) on November 10-11, 2009. No decongestants were detected in the Oxford WWTP inlet. Figure S2. Available dilution per capita per day at each of the River Thames sampling sites on each sampling occasion (November, 3, 10, 16, 24, 2009; March 15, 2010; May 11, 2011), dry weather flow (L/cap/d) and population. Figure S3. Atmospheric conditions on sampling days, including mean $(\mathrm{max} / \mathrm{min})$ temperature $\left({ }^{\circ} \mathrm{C}\right)$ and precipitation ('PP'; $\left.\mathrm{mm}\right)$, on the sampling day, 24-hours and 48-hours ahead of the Thames River sampling occasion. Figure S4. Percentage of samples in Benson and Oxford WWTPs $\left(\mathrm{n}_{\max }=24\right)$ and the river Thames $\left(\mathrm{n}_{\max }=84\right.$; only November) from which analytes were found above their LOQ. Analytes arranged by least to most frequently found in the River Thames, from left to right. Brown $=$ Benson WWTP influent; Blue $=$ Benson WWTP effluent; Yellow $=$ Oxford WWTP influent; Red = Oxford WWTP effluent; Black = River Thames.

Figure S5A. Concentration of antibiotics and oseltamivir (ng/L) 
at all river sampling locations for each of the sampling dates: November 3, 2009. River sampling locations given sorted by population upstream with TC8 having the smallest population. Figure S5B. Concentration of antibiotics and oseltamivir (ng/L) at all river sampling locations for each of the sampling dates: November 10, 2009. River sampling locations given sorted by population upstream with TC8 having the smallest population. Figure S5C. Concentration of antibiotics and oseltamivir (ng/L) at all river sampling locations for each of the sampling dates: November 16, 2009. River sampling locations given sorted by population upstream with TC8 having the smallest population.

Figure S5D. Concentration of antibiotics and oseltamivir (ng/L) at all river sampling locations for each of the sampling dates: November 24, 2009. River sampling locations given sorted by population upstream with TC8 having the smallest population. Figure S5E. Concentration of antibiotics and oseltamivir (ng/L) at all river sampling locations for each of the sampling dates: March 15, 2010. River sampling locations given sorted by population upstream with TC8 having the smallest population. Figure S5F. Concentration of antibiotics and oseltamivir (ng/L) at all river sampling locations for each of the sampling dates: May

\section{References}

1. Azuma T, Nakada N, Yamashita N, Tanaka H (2013) Mass balance of antiinfluenza drugs discharged into the Yodo River system, Japan, under an influenza outbreak. Chemosphere 93: 1672-1677.

2. Singer AC, Colizza V, Schmitt H, Andrews J, Balcan D, et al. (2011) Assessing the ecotoxicologic hazards of a pandemic influenza medical response. Environ Health Perspect 119: 1084-1090.

3. Chang CG, Cheng AC, Chang AB (2014) Over-the-counter (OTC) medications to reduce cough as an adjunct to antibiotics for acute pneumonia in children and adults. Cochrane Database Syst Rev 3: CD006088.

4. Dollery C (1999) Therapeutic Drugs. London: Harcourt Brace and Company Limited.

5. Knox C, Law V, Jewison T, Liu P, Ly S, et al. (2011) DrugBank 3.0: a comprehensive resource for 'omics' research on drugs. Nucleic Acids Res 39: D1035-1041.

6. Edlund A, Ek K, Breitholtz M, Gorokhova E (2012) Antibiotic-induced change of bacterial communities associated with the copepod Nitocra spinipes. PLoS One 7: e33107.

7. Singer AC, Nunn MA, Gould EA, Johnson AC (2007) Potential risks associated with the proposed widespread use of Tamiflu. Environmental Health Perspectives 115: 102-106.

8. Escher BI, Bramaz N, Lienert J, Neuwoehner J, Straub JO (2010) Mixture toxicity of the antiviral drug Tamiflu) (oseltamivir ethylester) and its active metabolite oseltamivir acid. Aquat Toxicol 96: 194-202.

9. Straub JO (2009) An environmental risk assessment for oseltamivir (Tamiflu) for sewage works and surface waters under seasonal-influenza- and pandemic-use conditions. Ecotoxicol Environ Saf 72: 1625-1634.

10. Hutchinson TH, Beesley A, Frickers PE, Readman JW, Shaw JP, et al. (2009) Extending the environmental risk assessment for oseltamivir (Tamiflu) under pandemic use conditions to the coastal marine compartment. Environ Int 35: 931-936.

11. Chen WY, Lin GJ, Liao CM (2014) Assessing exposure risks for aquatic organisms posed by Tamiflu use under seasonal influenza and pandemic conditions. Environ Pollut 184: 377-384.

12. Sacca ML, Accinelli C, Fick J, Lindberg R, Olsen B (2009) Environmental fate of the antiviral drug Tamiflu in two aquatic ecosystems. Chemosphere 75: 28-33.

13. Slater FR, Singer AC, Turner S, Barr JJ, Bond PL (2011) Pandemic pharmaceutical dosing effects on wastewater treatment: no adaptation of activated sludge bacteria to degrade the antiviral drug oseltamivir (Tamiflu) and loss of nutrient removal performance. FEMS Microbiol Lett 315: 17-22.

14. Singer AC, Howard BM, Johnson AC, Knowles CJ, Jackman S, et al. (2008) Meeting report: risk assessment of tamiflu use under pandemic conditions. Environ Health Perspect 116: 1563-1567.

15. Achenbach JE, Bowen RA (2013) Effect of oseltamivir carboxylate consumption on emergence of drug-resistant $\mathrm{H} 5 \mathrm{~N} 2$ avian influenza virus in Mallard ducks. Antimicrob Agents Chemother 57: 2171-2181.

16. Jarhult JD (2012) Oseltamivir (Tamiflu) in the environment, resistance development in influenza A viruses of dabbling ducks and the risk of transmission of an oseltamivir-resistant virus to humans - a review. Infect Ecol Epidemiol 2.

17. Gillman A, Muradrasoli S, Söderström H, Nordh J, Bröjer C, et al. (2013) Resistance Mutation R292K Is Induced in Influenza A(H6N2) Virus by
11, 2011. River sampling locations given sorted by population upstream with TC8 having the smallest population. Table S1. NHS BSA statistics on drug use in England from 2007-8. Predicted mass of drug used per day per WWTP catchment, using winter adjusted values, where the annual prescription rate was adjusted by a factor of $9.375 \%$ higher than the annual average rate (see text for details). Benson drug use rate was adjusted by a factor of 0.389 (the estimated fraction of the local PCT population within the Benson WWTP catchment; see text for details). na = data not available. Table S2. Literature review of oseltamivir in WWTP and rivers. Table S3. Liquid chromatography-tandem massspectrometry (LC-MS/MS) method parameters of study analytes. (DOCX)

\section{Author Contributions}

Conceived and designed the experiments: ACS JDJ JF HS. Performed the experiments: ACS JDJ RG GAK GF JF RHL MJB BO HS. Analyzed the data: ACS HS. Contributed reagents/materials/analysis tools: ACS JF MJB HS. Contributed to the writing of the manuscript: ACS HS.

Exposure of Infected Mallards to Low Levels of Oseltamivir. PLoS ONE 8: e71230

18. Jarhult JD, Muradrasoli S, Wahlgren J, Soderstrom H, Orozovic G, et al. (2011) Environmental levels of the antiviral oseltamivir induce development of resistance mutation $\mathrm{H} 274 \mathrm{Y}$ in influenza $\mathrm{A} / \mathrm{H} 1 \mathrm{~N} 1$ virus in mallards. PLoS One 6: e24742.

19. Wellington EM, Boxall AB, Cross P, Feil EJ, Gaze WH, et al. (2013) The role of the natural environment in the emergence of antibiotic resistance in gramnegative bacteria. Lancet Infect Dis 13: 155-165.

20. Gaze WH, Krone SM, Larsson DG, Li XZ, Robinson JA, et al. (2013) Influence of humans on evolution and mobilization of environmental antibiotic resistome. Emerg Infect Dis 19.

21. World Health Organization (2010) WHO recommendations for the postpandemic period: Pandemic (H1N1) 2009 briefing note 23. Available: http:// www.who.int/csr/disease/swineflu/notes/briefing_20100810/en/. Accessed 2012 Jun 1.

22. Bowes MJ, Jarvie HP, Naden PS, Old GH, Scarlett PM, et al. (2014) Identifying priorities for nutrient mitigation using river concentration-flow relationships: The Thames basin, UK. Journal of Hydrology 517: 1-12.

23. Harvey CL, Dixon H, Hannaford J (2012) An appraisal of the performance of data-infilling methods for application to daily mean river flow records in the UK. Hydrology Research 43: 618-636.

24. TuTiempo.net (2009) Climate: Benson (November, 2009). Available: http:// www.tutiempo.net/en/Climate/Benson/11-2009/36580.htm. Accessed 2012 Oct 26.

25. Prasse C, Schlusener MP, Schulz R, Ternes TA (2010) Antiviral drugs in wastewater and surface waters: a new pharmaceutical class of environmental relevance? Environ Sci Technol 44: 1728-1735.

26. Balcan D, Colizza V, Singer AC, Chouaid C, Hu H, et al. (2009) Modeling the critical care demand and antibiotics resources needed during the Fall 2009 wave of influenza $\mathrm{A}(\mathrm{H} 1 \mathrm{~N} 1)$ pandemic. PLoS Curr 1: RRN1133.

27. Khan GA, Lindberg R, Grabic R, Fick J (2012) The development and application of a system for simultaneously determining anti-infectives and nasal decongestants using on-line solid-phase extraction and liquid chromatographytandem mass spectrometry. J Pharm Biomed Anal 66: 24-32.

28. NHS BSA (2011) Prescribing Analysis Charts: National Antibiotics Charts. Available: http://www.nhsbsa.nhs.uk/PrescriptionServices/2587.aspx. Accessed 2012 Oct.

29. NHS Information Centre for Health and Social Care (2011) Number of GP Prescriptions by drug by postcode. Available: http://data.gov.uk/apps/numberof-gp-prescriptions-by-drug-by-postcode.

30. Health Protection Agency (2010) Epidemiological report of pandemic (H1N1) 2009 in the UK (April 2009 - May 2010). Available: http://www.hpa.org.uk/ webc/HPAwebFile/HPAweb_C/1284475321350. Accessed 2012 Jun 1.

31. Rogers S, Sedghi A (2011) Swine flu data in the UK: see how bad cases are where you live. Guardian Available: http://www.guardian.co.uk/news/ datablog/2011/jan/06/swine-flu-data-uk\#data. Accessed 2012 Jun 1.

32. The Health and Social Care Information Centre PSU (2012) Average Daily Quantities. Available: http://www.ic.nhs.uk/services/prescribing-support-unit$\mathrm{psu} /$ using-the-service/reference/measures/volume-measures/average-dailyquantities-adq. Accessed 2012 Oct 19. 
33. Davey P, Ferech M, Ansari F, Muller A, Goossens H (2008) Outpatient antibiotic use in the four administrations of the UK: cross-sectional and longitudinal analysis. Journal of Antimicrobial Chemotherapy 62: 1441-1447.

34. Singer AC, Jarhult JD, Grabic R, Khan GA, Fedorova G, et al. (2013) Compliance to oseltamivir among two populations in Oxfordshire, United Kingdom affected by influenza A(H1N1) pdm09, November 2009-a waste water epidemiology study. PLoS One 8: e60221.

35. Azuma T, Nakada N, Yamashita N, Tanaka H (2012) Synchronous dynamics of observed and predicted values of anti-influenza drugs in environmental waters during a seasonal influenza outbreak. Environ Sci Technol 46: 12873-12881.

36. Takanami R, Ozaki H, Giri RR, Taniguchi S, Hayashi S (2012) Antiviral Drugs Zanamivir and Oseltamivir Found in Wastewater and Surface Water in Osaka, Japan. Journal of Water and Environment Technology 10: 57-68.

37. Leknes H, Sturtzel IE, Dye C (2012) Environmental release of oseltamivir from a Norwegian sewage treatment plant during the 2009 influenza A (H1N1) pandemic. Sci Total Environ 414: 632-638.

38. Ghosh GC, Nakada N, Yamashita N, Tanaka H (2010) Occurrence and fate of oseltamivir carboxylate (Tamiflu) and amantadine in sewage treatment plants. Chemosphere 81: 13-17.

39. Ghosh GC, Nakada N, Yamashita N, Tanaka H (2010) Oseltamivir carboxylate, the active metabolite of oseltamivir phosphate (Tamiflu), detected in sewage discharge and river water in Japan. Environ Health Perspect 118: 103-107.

40. Fick J, Lindberg RH, Tysklind M, Haemig PD, Waldenstrom J, et al. (2007) Antiviral oseltamivir is not removed or degraded in normal sewage water treatment: implications for development of resistance by influenza A virus. PLoS One 2: e986.

41. Takanami R, Ozaki H, Giri RR, Taniguchi S, Hayashi S (2010) Detection of antiviral drugs oseltamivir phosphate and oseltamivir carboxylate in Neya River, Osaka Japan. Journal of Water and Environment Technology 8: 363-372.

42. Kohring GW, Rogers JE, Wiegel J (1989) Anaerobic biodegradation of 2,4dichlorophenol in freshwater lake sediments at different temperatures. Applied and Environmental Microbiology 55: 348-353.

43. Atlas RM (1975) Effects of Temperature and Crude Oil Composition on Petroleum Biodegradation. Applied Microbiology 30: 396-403.

44. Michael I, Rizzo L, McArdell CS, Manaia CM, Merlin C, et al. (2013) Urban wastewater treatment plants as hotspots for the release of antibiotics in the environment: a review. Water Res 47: 957-995.

45. Luo Y, Guo W, Ngo HH, Nghiem LD, Hai FI, et al. (2014) A review on the occurrence of micropollutants in the aquatic environment and their fate and removal during wastewater treatment. Sci Total Environ 473-474: 619-641.

46. Lindberg RH, Ostman M, Olofsson U, Grabic R, Fick J (2014) Occurrence and behaviour of 105 active pharmaceutical ingredients in sewage waters of a municipal sewer collection system. Water Res 58C: 221-229.
47. Kardas P (2002) Patient compliance with antibiotic treatment for respiratory tract infections. J Antimicrob Chemother 49: 897-903.

48. Llor C, Hernandez S, Bayona C, Moragas A, Sierra N, et al. (2013) A study of adherence to antibiotic treatment in ambulatory respiratory infections. Int J Infect Dis 17: e168-172.

49. McNulty CA, Boyle P, Nichols T, Clappison P, Davey P (2007) The public's attitudes to and compliance with antibiotics. J Antimicrob Chemother $60 \mathrm{Suppl}$ 1: i63-68.

50. Ort C, Lawrence MG, Reungoat J, Mueller JF (2010) Sampling for PPCPs in wastewater systems: comparison of different sampling modes and optimization strategies. Environ Sci Technol 44: 6289-6296.

51. Ort C, Gujer W (2006) Sampling for representative micropollutant loads in sewer systems. Water Sci Technol 54: 169-176.

52. Ort C, Schaffner C, Giger W, Gujer W (2005) Modeling stochastic load variations in sewer systems. Water Sci Technol 52: 113-122.

53. Ort C, Lawrence MG, Rieckermann J, Joss A (2010) Sampling for pharmaceuticals and personal care products (PPCPs) and illicit drugs in wastewater systems: are your conclusions valid? A critical review. Environ Sci Technol 44: 6024-6035.

54. Gillman A, Muradrasoli S, Soderstrom H, Nordh J, Brojer C, et al. (2013) Resistance mutation $\mathrm{R} 292 \mathrm{~K}$ is induced in influenza $\mathrm{A}(\mathrm{H} 6 \mathrm{~N} 2)$ virus by exposure of infected mallards to low levels of oseltamivir. PLoS One 8: e71230.

55. Ivachtchenko AV, Ivanenkov YA, Mitkin OD, Yamanushkin PM, Bichko VV, et al. (2013) A novel influenza virus neuraminidase inhibitor AV5027. Antiviral Res 100: 698-708.

56. Wathen MW, Barro M, Bright RA (2013) Antivirals in seasonal and pandemic influenza-future perspectives. Influenza Other Respir Viruses 7 Suppl 1: 76-80.

57. Jefferson T, Jones MA, Doshi P, Del Mar CB, Hama R, et al. (2014) Neuraminidase inhibitors for preventing and treating influenza in healthy adults and children. Cochrane Database Syst Rev 4: CD008965.

58. Drinking Water Inspectorate (2007) Desk based review of current knowledge on pharmaceuticals in drinking water and estimation of potential levels (Defra Project Code: CSA 7184/WT02046/DWI70/2/213). Available: http://googl/ nkBVlP.

59. Perelson AS, Rong L, Hayden FG (2012) Combination Antiviral Therapy for Influenza: Predictions From Modeling of Human Infections. Journal of Infectious Diseases 205: 1642-1645.

60. Kim W-Y, Young Suh G, Huh JW, Kim S-H, Kim M-j, et al. (2011) TripleCombination Antiviral Drug for Pandemic H1N1 Influenza Virus Infection in Critically Ill Patients on Mechanical Ventilation. Antimicrobial Agents and Chemotherapy 55: 5703-5709. 